\title{
Revisión del concepto clase política y análogos en la historia del departamento de Caldas*
}

\author{
[Versión en Castellano] \\ Revision of the Concept of Political Class and Analogues in the \\ History of the Department of Caldas
}

Revisão do conceito de classe política e analogias na história do departamento de Caldas

Recibido el 23 de agosto, 2019. Aceptado el 1 de junio, 2020.

Julio Cruz**

https://orcid.org/0000-0002-5867-6930

Colombia

\section{Resumen}

- Para citar este artículo:

Cruz, Julio (2021). Revisión del concepto clase política y análogos en la historia del departamento de

Caldas. Ánfora, 28(50), 297-321

https://doi.org/10.30854/anfv28.n50.2021.649

Universidad Autónoma de

Manizales. ISSN 0121-6538/

e-ISSN 2248-6941.

CC BY-NC-SA 4.0
Objetivo: artículo de Revisión que busca identificar los desarrollos teóricos del concepto clase política y análogos; además, se trata de captar las diferencias de dichos conceptos para mostrar las transformaciones de la clase política en Caldas. Metodología: se aplicó metaanálisis cualitativo de los hallazgos, los cuales derivaron de la búsqueda documental en torno a los mencionados conceptos clave, a partir de determinadas categorías y criterios de análisis. Resultados: se llegó a una definición de clase política, entendida como grupo de individuos que tienen una relación orgánica con la política e

\footnotetext{
* El presente artículo de Revisión es producto de la tesis titulada: "La secta del fénix. La formación discursiva del paramilitarismo en Caldas (1980-2006)", para optar al título de Magíster en estudios políticos de la Universidad de Caldas. La financiación del proyecto fue asumida por el investigador, quien declara que no hubo conflicto de intereses en la ejecución del proyecto de investigación.

** Sociólogo. Estudiante tesista de Maestría en estudios políticos, Universidad de Caldas, Manizales, Caldas, Colombia. Correo: julio.9619131581@ucaldas.edu.co
} 
intereses directos puestos en ella; esto, independientemente de que ejerzan o no un cargo público, aunque sí el poder político, como la posibilidad de tomar decisiones que afecten a los miembros de la esfera pública. Con esta categorización se hizo un análisis de los usos de estos conceptos en Colombia y Caldas. Allí se muestran las continuidades y transformaciones de su clase política desde la Colonización Antioqueña hasta la época actual, y se especifica su configuración como grupo dirigente y el papel desempeñado en el devenir del departamento. Conclusiones: se destaca el carácter cíclico de la política caldense en relación con sus élites políticas a la luz de los acontecimientos recientes. También se confirma la afirmación clásica en cuanto a la teoría de las élites, la cual asume estas agrupaciones como una constante en todas las democracias.

Palabras-clave: Ciencia política; Clase política; Oligarquía; Élite política; Clase dominante; Caldas-Colombia.

\section{Abstract}

Objective: Review article that seeks to identify the theoretical developments of the concept of political class and its analogues; in addition, it is about capturing the differences of these concepts to show the transformations of the political class in Caldas. Methodology: a qualitative meta-analysis of the findings was applied, which were derived from the documentary search around the aforementioned key concepts, based on certain categories and analysis criteria. Results: a definition of political class was reached, understood as a group of individuals who have an organic relationship with politics and direct interests placed in it; this, regardless of whether or not they hold public office, although they do hold political power, such as the possibility of making decisions that affect members of the public sphere. With this categorization, an analysis was made of the uses of these concepts in Colombia and Caldas. There the continuities and transformations of its political class are shown from the Antioquia Colonization to the present time, and its configuration as a leading group and the role played in the future of the department are specified. Conclusions: it highlights the cyclical nature of Caldense politics in relation to its political elites in light of recent events. The classic statement regarding the theory of elites is also confirmed, which assumes these groupings as a constant in all democracies.

Keywords: Political science; Political class; Oligarchy; Political elite; Dominant class; Caldas-Colombia. 


\section{Resumo}

Objetivo: artigo de revisão que busca identificar os desdobramentos teóricos do conceito de classe política e seus análogos; além disso, trata-se de captar as diferenças desses conceitos para mostrar as transformações da classe política em Caldas. Metodologia: aplicou-se uma meta-análise qualitativa dos achados, derivados da busca documental em torno dos conceitos-chave mencionados, com base em determinadas categorias e critérios de análise. Resultados: chegou-se a uma definição de classe política, entendida como um conjunto de indivíduos que têm uma relação orgânica com a política e interesses diretos nela colocados; isto, independentemente de exercerem ou não cargos públicos, embora detenham poder político, como a possibilidade de tomar decisões que afetam membros da esfera pública. Com essa categorização, foi feita uma análise dos usos desses conceitos na Colômbia e Caldas. Nela se mostram as continuidades e transformações de sua classe política desde a colonização de Antioquia até a atualidade, especificando-se sua configuração como grupo dirigente e o papel desempenhado no futuro do departamento. Conclusões: destaca a natureza cíclica da política caldense em relação às suas elites políticas à luz dos acontecimentos recentes. Também se confirma a afirmação clássica a respeito da teoria das elites, que assume esses agrupamentos como uma constante em todas as democracias.

Palabras-chave: Ciência Política; Classe política; Oligarquia; Elite política; Classe dominante; Caldas-Colômbia. 


\section{Introducción}

La diferencia que marca un grupo de personas que desempeña funciones de gobierno con los gobernados, ha sido un tema de debate desde épocas remotas. Esta división social no fue ajena a la tradición filosófica clásica, pues desde allí se ha convertido en campo de investigación para disciplinas de las ciencias sociales. A partir del legado filosófico helénico, que se hacía preguntas sobre la minoría acaudalada que ejercía el poder, llamada oligarquía, la sociología ha debatido acerca de las relaciones sociales inherentes a la constitución de las élites, y la ciencia política ha querido hacer de este campo uno de sus objetos de estudio.

Los desarrollos de estas ideas van desde las posiciones que conciben una élite monolítica y cerrada hasta las que hablan de pluralismo, desde las visiones positivas de la división entre gobernantes y gobernados hasta las que se acogen a la tradición de homologar oligarquía con avaricia. La discusión sostenida durante varios años entre las escuelas de pensamiento alrededor de este tema ha retroalimentado las posturas y llevado a conclusiones que ofrecen una mirada más aguda y profunda de la cuestión.

Para el caso de las regiones, también existen análisis que dan cuenta de las particularidades del ejercicio del poder en contextos administrativamente menos extensos que el Estado-nación, las divergencias que se presentan entre uno y otro, sus continuidades y puntos convergentes. Igualmente, es importante tener en cuenta el papel de los conflictos armados en la configuración de las élites y las relaciones establecidas entre los violentos y los políticos profesionales.

El presente estudio desarrolla una Revisión bibliográfica con la que se construye un cuerpo teórico desde el que se interpreta el desarrollo de la clase política en Colombia y, particularmente, en el departamento de Caldas, toma como punto de partida histórico el proceso de la Colonización Antioqueña y llega hasta la actualidad. El análisis y comparación de estos conceptos, comúnmente utilizados tanto por académicos como por el público general, deberá mostrar la capacidad heurística de los mismos en el contexto caldense, la pertinencia, limitaciones y precisión de su aplicación; en este sentido, servirá como soporte teórico que enriquezca el debate y la reflexión académica y política en la región en relación con su sector dirigente, sus perspectivas y el papel que juega la ciudadanía en su configuración, actualidad y eventual cambio, de ser ello necesario.

\section{Metodología}

El camino metodológico de este artículo de Revisión, se basó en compilación de trabajos de investigación en torno a los conceptos élites políticas, oligarquía, 
clase dirigente, clase política y corporativismo como términos, específicamente en el departamento de Caldas y un panorama general para el caso colombiano.

Los textos de análisis fueron seleccionados bajo los siguientes criterios: referidos al tema de las relaciones públicas de poder, esto es, a la política, concretamente a las minorías gobernantes bajo los conceptos ya mencionados; la trascendencia de sus postulados, lo que permite considerarlos clásicos de esta temática; su actualidad en relación con los contextos nacional y regional; referidos a la historia política del departamento de Caldas en el periodo de tiempo abordado del año 1980 a 2006.

La información recopilada se categorizó de acuerdo con esta tipificación y se hace el correspondiente análisis, consistente en el relacionamiento entre los autores y sus postulados, para lo cual se tuvo como guía el planteamiento de Sartori (1970) sobre la comparación de conceptos en ciencia política. Dicho análisis está determinado por las categorías de gobierno de minorías, poder público, relaciones de poder, ejercicio del poder y teoría de las élites.

\section{Resultados}

\section{Oligarquia, élite, clase política... Avatares de una definición}

No existe consenso en ciencias sociales sobre cómo nominar conceptualmente los grupos sociales que ejercen el poder. No obstante, sí puede encontrarse una copiosa bibliografía al respecto. Bobbio $(1981,1982)$ hace un importante aporte a esta discusión a partir de los conceptos de oligarquía y teoría de las élites. En lo que respecta a la primera, este autor destaca dos tradiciones: la que lo usa en sentido peyorativo, como sinónimo de gobierno de los ricos y la que lo aplica de manera descriptiva para referirse al gobierno de unos pocos, acepción más cercana a su etimología.

Por otro lado, el concepto de clase política aparece en Mosca (1984) y el de clase dominante es propio de buena parte de la tradición marxista. En cuanto al concepto de élite, el debate se asumirá con base en la discusión elitismo/pluralismo/marxismo que le es propia. A continuación se muestran los principales hallazgos con base en la trascendencia y/o actualidad de las teorías desarrolladas y las definiciones suministradas, en relación con el ejercicio público del poder, sus relaciones y el gobierno de minorías. 


\section{Oligarquia.}

En la búsqueda del poder discriminatorio del concepto en cuestión (Sartori, 1970), puede afirmarse que hay consenso entre los exponentes de la filosofía política, tanto clásica como moderna, en lo que respecta al carácter positivo/ negativo de la díada aristocracia/oligarquía respectivamente y a la oposición de esta última con la democracia.

La oligarquía es definida, según la tradición griega antigua -de donde emerge el término- como el gobierno en el que les corresponde a los ricos el mandato, toda vez que la organización social se sustenta en las posesiones individuales (Platón, 1986, p. 238); constituye una forma de gobierno pervertida en relación con la aristocracia, forma de gobierno por antonomasia (pp. 232-233), en la medida en que gobierna para sí misma y no para los súbditos (Aristóteles, 2004, p. 96); es decir, deviene forma degenerada de esta, toda vez que el privilegio recae en la posesión de riqueza, lo cual controvierte los principios morales del gobierno (Rousseau, 2004, p. 101).

Las razones de dicha corrupción residen en la herencia del poder por la nobleza, la cual aparece ya cuando aquella gobierna para sí misma en lugar de hacerlo para los súbditos (Montesquieu, 1984, p. 114), o en otras palabras, del predominio de la avaricia sobre la virtud (Platón, 1986, p. 232).

A primera vista puede parecer que la definición de oligarquía se circunscribe a la posesión de riqueza de quienes ejercen el gobierno, motivo principal de su carácter despectivo, principalmente en la tradición griega clásica (Bobbio, 1982 , p. 1118) y se alejaría de la idea de gobierno de unos pocos, como lo señala su etimología. Pero una mirada más atenta muestra que, en la medida en que la oligarquía se presenta como la forma negativa de la aristocracia o gobierno de los más capacitados de una sociedad, la idea de minoría está implícita, toda vez que en cualquier grupo social tanto los mejores como los ricos suelen ser pocos (Aristóteles, 2004, p. 96), lo que refuerza el carácter despectivo que esta denominación posee hasta el día de hoy (Bobbio, 1982, p. 1118).

Este argumento no termina de satisfacer la necesidad de definición exhaustiva del concepto, ya que elude el debate sobre la esencia de la oligarquía en relación con la minoría o la riqueza. En la misma línea va la consideración de la democracia como gobierno de los pobres (Platón, 1986, pp. 232-233), los cuales habría que considerar como mayoritarios. Se puede plantear que la llegada a la administración del Estado de partidos obreros cumple con el precepto de la minoría pero no con el de la riqueza y, aun así, constituir una oligarquía.

Otras definiciones que se escapan de este marco comparativo (Sartori, 1970) se refieren a la oligarquía simplemente como el nombre que sus súbditos inconformes le dan a la aristocracia (Hobbes, 1994, p. 151), o como la forma de 
gobierno que deja la potestad de hacer las leyes a unos pocos hombres selectos (Locke, 1985, p. 91), sin mencionar nada acerca de su riqueza, pero sí haciendo alusión al carácter minoritario de dicha forma de gobierno. Así pues, el concepto de oligarquía posee más utilidad cuando se asume en su acepción de gobierno de pocos que cuando se lo toma como gobierno de ricos, ya que esta última acarrea las problemáticas ya señaladas.

\section{Teoria de las élites.}

Desde otro enfoque teórico el carácter despectivo del término oligarquía se aminora, toda vez que la idea de gobierno de los acaudalados pierde peso. La teoría de las élites se sustenta en la idea que "todos los gobiernos que existieron y los que existirán han sido siempre gobiernos de pocos (...), gobiernos de minorías organizadas, o de élites" (Bobbio, 1982, p. 1119), ergo, son oligárquicos. Así las cosas, tanto en las democracias como en las monarquías los gobernantes constituyen un grupo organizado que detenta el poder político, independientemente de su condición económica (aunque la presunción de Aristóteles se muestre vigente).

El desarrollo de esta teoría se apoya en la sociología, para afirmar que se debe observar el grado y magnitud de organización de la élite gobernante para comprender las fuentes de su poder. De allí deriva la tesis de la existencia en todos los organismos políticos de una clase gobernada y otra gobernante, que luego se llama indistintamente clase dirigente o política (Mosca, 1984, p. 87). Otra corriente se preocupó más por las luchas entre las élites; las relaciones entre estas llevan a una teoría del equilibrio social (Pareto, 1980).

Aplicaciones de la primea corriente mencionada han sido probadas a una escala menor, ya que esta se refería a grandes grupos sociales (el Estado o gobiernos regionales y locales), mediante el trabajo empírico en partidos políticos que mostró cómo en estos contextos también operan diferencias entre una masa dirigida y una élite dirigente (Michels, 1972) a la que, por cierto, se llama oligarquía; de hecho, este teórico es el autor de la afamada ley férrea de la oligarquía, expuesta en los siguientes términos: "La organización es la que da origen al dominio de los elegidos sobre los electores, de los mandatarios sobre los mandantes, de los delegados sobre los delegantes. Quien dice organización, dice oligarquía" (Michels, 1972, p. 189).

Esta teoría parte de una definición convergente de las élites, entendidas como aquellos grupos sociales que ocupan los estratos sociales superiores en términos de poder y riqueza, y las élites políticas como las que tienen la capacidad de tomar decisiones que afectan a los miembros del grupo al que pertenecen (Bolívar, 2002); esto confirma su pertenencia a un mismo cuerpo conceptual 
convergente, caracterizado por la mirada conservadora y monolítica de las élites, crítica de la democracia liberal, pero diferenciable de otras tradiciones referidas al mismo fenómeno, con los cuales puede ser comparado (Sartori, 1970).

Desarrollos ulteriores de esta mirada sociológica han llevado a lo que se denomina características sociales de las élites (Coller, 1999). En este orden de ideas se traen a colación análisis centrados en la idea de que los orígenes sociales y la educación tienen un peso específico en la conformación de las élites políticas (Mills, 1987, pp. 25-26). A esto se agrega que las características sociales de las élites tienden a ser similares, con lo que se configura una especie de casta sociopolítica dominante (Putman, 1976), opinión que comparten otros autores que observaron el caso estadounidense (Coller, 1999). Estas tesis también se inscriben en la vertiente monolítica de las élites, diferenciables del abordaje anteriormente analizado básicamente por tratar asuntos más actuales y por ende en el marco de unas relaciones sociales más complejas.

Corrientes liberales y pluralistas han hecho críticas al carácter monolítico de la élite que Mills (1987) presenta, y sostienen que en sociedades complejas, como la estadounidense, existen varias élites que pugnan por el poder y se lo reparten, algo que va en la vía de la idea de Putman (1976). En este orden de ideas, se habla de la imposibilidad de probar empíricamente la tesis de la élite monolítica de Mills (1987) al mostrar que la composición de esta no está bien definida (Dahl, 1958, p. 466). Otra perspectiva agrega que la característica fundamental de la competencia entre élites en las democracias es la lucha por el voto popular (Schumpeter, 1983, nuevamente en consonancia con Putman, 1976, pp. 359-360). Así las cosas, puede mencionarse el postulado de Aron (1950) sobre la diferencia entre la élite soviética organizada y unificada y las élites occidentales divididas (p. 10). Otra idea sostiene que no es posible constreñir el análisis del poder en general y de las élites en particular, y propone abordar la cuestión teniendo en cuenta tanto las dimensiones explícitas como las ocultas (Lukes, 2007, p. 69).

Una postura cercana al pluralismo, pero alejada del liberalismo es la encarnada por el neocorporatismo, corriente que bebe de la fuente del Estado Benefactor keynesiano y que concibe la relación entre las élites como una negociación en la que todos los grupos pueden obtener participación e influencia, a cambio de ceder en algunas de sus pretensiones, toda vez que ninguno de estos grupos tiene la capacidad suficiente para imponer sus intereses a los demás.

La negociación se concierta con el Estado mismo, dado que esta corriente parte del presupuesto de unas relaciones sociales capitalistas, y que el Estado no tiene autonomía frente a dichas élites. El objetivo fundamental de este enfoque es "la concertación interorganizativa, esto es, la negociación entre un grupo limitado y excluyente de organizaciones, las cuales se reconocen mutuamente el status 
y la capacidad de alcanzar y aplicar unos compromisos relativamente estables" (Schmitter, 1985, p. 67).

Otros abordajes contemporáneos se han centrado en las características de las élites políticas más allá de la simplista y mecánica división entre los gobernantes y la masa gobernada, lo que incluye los tipos de élites, sus cualidades, sus formas de reclutamiento entre otros y se deriva en la consideración del estudio de las élites como grupo social específico (Blondel y Müller-Rommel, 2007); la influencia de los rasgos de la personalidad de los miembros de la élite política en las decisiones públicas de una unidad territorial (Arana-Araya, 2016); además, las características de las élites como base de la formación de coaliciones sociopolíticas y la definición de las variaciones de los partidos políticos (Best y Cotta, 2000; Lispet y Rokkan, 1967). Por ende, en este caso es dable decir que el concepto de teoría de las élites tiene una utilidad analítica holística, ya que tanto la postura conservadora y monolítica como las críticas pluralistas y neocorporativas permiten configurar una mirada amplia del fenómeno aquí abordado, en relación tanto con su lógica interna como con los aspectos externos relativos a los diferentes tipos de sociedad de que se hable.

\section{Clase política.}

Los siguientes autores son explícitos en marcar una diferencia teórica entre clase política y élite política:

A diferencia del concepto de élite política, el de clase política no alude específicamente a los individuos que detentan posiciones de especial poder e influencia, sino que se refiere al grupo, más extenso y también más fácilmente identificable, de los individuos que viven de la política y que poseen intereses y perspectivas peculiares como consecuencia de las posiciones que ocupan y de los papeles que desempeñan en la vida social (Alcántara y Llamazares, 1997, pp. 15-16).

Así pues, la élite política se refiere aquí a los políticos profesionales, no necesariamente relacionados con la oligarquía y más cercanos a la idea de tecnócratas de la administración pública. El término clase política tiene mucha presencia en la literatura sobre élites -como se vio en Bobbio (1981)-, no obstante su uso suele ser distendido y genérico. Parece que frente a esta denominación se está en presencia de una referencia carente de cuerpo conceptual sobre el cual puedan hacerse análisis con pretensión científica (Sartori, 1970). Sin embargo, se conserva para mantener la posibilidad de comparación con los demás conceptos abordados y porque su uso en la ciencia política es extendido. 


\section{Clase dominante.}

Desde la otra orilla ideológica, el marxismo ha hecho críticas a la teoría de las élites en su conjunto. Para los representantes de esta escuela de pensamiento, la versión pluralista de la teoría de las élites es incompatible con la realidad social, puesto que el poder político está concentrado de manera casi exclusiva en quienes ostentan la propiedad privada sobre los medios de producción. De ahí surge el concepto de clase dominante, versión marxista de la de élite u oligarquía. El concepto de clase se torna fundamental en esta corriente, y se refiere al agrupamiento social de los sujetos de acuerdo con su posición con respecto a los medios de producción; sus poseedores conforman los diferentes sectores de la burguesía, mientras que los desposeídos engrosan las filas de la masa proletaria (Marx y Engels, 1973, pp. 31-32).

Ahora bien, hay en la tradición marxista un concepto que se relaciona con el debate por el poder político, pero no homologable con la idea clásica de la dictadura del proletariado, en la que esta clase social asume por la fuerza el control del Estado para instituir desde allí el socialismo y socavar la contrarrevolución burguesa. El concepto de hegemonía considera el aspecto cultural como una posibilidad estratégica para mantener los objetivos revolucionarios una vez alcanzada la victoria política, para lo cual se combinan el consenso y la fuerza:

El ejercicio "normal” de la hegemonía... está caracterizado por una combinación de la fuerza y del consenso que se equilibran, sin que la fuerza supere demasiado al consenso, sino que más bien aparezca apoyada por el consenso de la mayoría expresado por los llamados órganos de la opinión pública (Gramsci, 1981, p. 124).

Dichos órganos de la opinión pública son las instituciones de la sociedad civil creadas voluntariamente, y que sirven para difundir las ideas de los gobernantes (prensa, iglesia, partidos, escuelas, ONG, grupos de investigación etc.). Esta es una de las dos tácticas que garantizan la hegemonía de los gobernantes; la otra es el grupo de intelectuales que se encargan de comunicar las ideas dominantes a los dominados, sin dejar de lado la posibilidad de la represión cuando fuera menester. Así las cosas, "la hegemonía... incluía tanto la obtención por los gobernantes del consentimiento de los gobernados como la aplicación de la coerción necesaria para hacer cumplir sus órdenes" (Anderson, 2018, p. 31). A pesar de que el concepto de clase dominante es cada vez más extraño en la literatura sobre política, sus aportes no dejan de estar presentes en el debate, y continúa teniendo utilidad dado su poder heurístico frente al fenómeno del poder en la actualidad. 
Así pues, y luego de llevar a cabo un ejercicio comparativo de los conceptos que se refieren a las minorías en el poder (Sartori, 1970), para efectos del presente artículo se apelará al concepto de clase política entendido como el grupo de individuos que tienen una relación orgánica con la política e intereses directos puestos en ella, independientemente de que ejerzan o no un cargo público (Alcántara y Llamazares, 1997, pp. 15-16), pero teniendo claro que sí pueden ejercer el poder político, entendido como la posibilidad de tomar decisiones que afecten a los miembros de la esfera pública (Bolívar, 2002, p. 388). Se prefiere esta definición a la de élite, puesto que esta tiene una connotación muy cercana a la de aristocracia, entendida como minoría selecta, o sea superior, y por ende mejor facultada para ejercer funciones rectoras, en la línea de Platón (1986) y Aristóteles (2004).

Tampoco es adecuado el concepto de oligarquía, dada su carga semántica negativa y el marcado uso ideológico que ha adquirido, pero se resaltan las proximidades conceptuales de todas las tradiciones teóricas abordadas. Por ende, el concepto de clase política abarca a los demás y alude a clase no en el sentido marxista que la vincula con el aspecto económico, sino como agrupación de individuos, es decir, en clave sociológica.

\section{La constitución de la clase política en Caldas}

Cuando se pasa del análisis nacional al regional, debe tenerse en cuenta que hay una diferencia entre lo uno y lo otro que consiste en las diferentes dinámicas políticas que operan en cada escenario. La tendencia del país a tener unas pocas familias o grupos políticos predominantes se observa igualmente en el caso caldense, como se verá más adelante, sin que se hable siempre de los mismos grupos. En las regiones existen unas élites que controlan con carácter oligárquico las posiciones estratégicas de la administración pública, pero estas no necesariamente tienen la misma influencia en el plano nacional; su dominio se circunscribe, en la mayoría de los casos, a su localidad (Jaramillo, 2009).

Situación diferente es que las élites regionales tengan interlocución con la administración nacional, lo que va en beneficio propio, como es el caso de Caldas. Así pues, una tesis como la de Ávila (2018) no se contradiría con la realidad en las regiones. Por otro lado, también es pertinente señalar que la violencia ha sido un fenómeno que ha contribuido en buena medida a la configuración de las élites regionales a lo largo de la historia del país, desde los procesos de independencia hasta el conflicto armado reciente, pasando por el periodo posterior al magnicidio de Gaitán; Caldas no ha sido ajena a esta situación (Christie, 1986; Jaramillo, 2009; Rivas, 2016). 


\section{La Colonización Antioqueña.}

Sobre este proceso es mucho lo que se ha dicho en cuanto a las razones que tratan de explicar su desarrollo. Una de las controversias que se presentan entre los autores que han escrito sobre la mencionada colonización tiene que ver con el carácter social de esta. Por ejemplo, el cacique político manizaleño Luis Guillermo Giraldo afirma que hay que establecer una diferencia entre colonización y fundación: la colonización fue popular, campesina y espontánea; la fundación fue hecha por élites (Giraldo, 2015, p. 354). Pero los detalles de este proceso exceden los propósitos de este artículo.

Lo cierto es que, sea como iniciadores o como continuadores, los sectores económica y políticamente privilegiados de Antioquia asumieron pronto la dirección de la colonización y su consecuente dominio sobre el recién fundado territorio. Pruebas de ello son la manera como se resuelven conflictos de intereses entre los colonos pobres y los dueños y herederos de las antiguas concesiones coloniales, como la Aranzazu y la Villegas, con la aparición de actores nuevos como la sociedad González Salazar y Compañía, empresa comercial de predios rurales que actuó en defensa de los intereses de los propietarios legales (si bien no habitantes ni productores) de los predios. La pugna entre Juan de Dios Aranzazu, heredero de la mencionada concesión y, a la postre, presidente de la República, y los habitantes de sus territorios, muestra esta relación entre poseedores y desposeídos:

No podía el doctor Aranzazu de hacer honor a los anteriores Capituladores. Ha repartido tierras pero no son las mejores ni las más cercanas, ni las que tienen más claro el título jurídico. Y no echa a los colonos que no alcanzaron tierras sino que los incita a que sigan tumbando selva y abriendo sementeras para que así, cuando él pueda organizarse e ir a reclamarlas, las encuentre desarrolladas y en producción (De los Ríos, 1983, p. 435).

En medio de estas coyunturas jurídicas se siguen fundando los municipios de Caldas, muchos de ellos antes de la fecha de formalización del departamento como unidad administrativa diferente de Antioquia en 1905. Y pronto, en estos municipios, se destacará un grupo con poder económico y político que tomará el lugar de las viejas estructuras coloniales y establecerá una forma de dominación oligárquica que mezclará formas de producción latifundistas con poder político basado en el linaje, los apellidos y la tradición (Ocampo, 1972; Christie, 1986).

Ahora, la idea de oligarquía, expuesta por Ocampo (1972, pp. 13-22) y Christie (1986, pp. 37-47) en una clave marxista, explícita en el primero y redomada en el segundo, se basa en la organización cerrada de las familias que hacia 
mediados del siglo XIX ya ejercían control político y económico en Manizales y otros municipios de esta región de manera casi exclusiva y excluyente, lo cual redunda en el sometimiento de los demás grupos sociales y en una postulación eminentemente negativa del citado concepto, de acuerdo con Bobbio (1982).

Este proceso se verá fortalecido por el rápido progreso económico vivido por Manizales después de 1850, cuando factores como su ubicación estratégica y las guerras civiles de 1860 y 1874 contribuyeron a que este pueblo ubicado en la cima de una montaña atrajera comerciantes, mineros y hombres de negocios de otras latitudes para hacer inversiones allí:

De este modo se observan dos etapas en la colonización. La primera, abarca la producción de artículos de subsistencia en las parcelas de los colonos durante los primeros años, y cuando estos productos no cuentan con buen mercado. La segunda, a partir de la valorización de la tierra por el incremento del mercado para los productos agrícolas de subsistencia o por las posibilidades de la producción de artículos comerciales como el tabaco, caña o pasto para ganadería (Valencia, 1990, p. 211).

Esto empoderaría económica y políticamente a la ya mencionada oligarquía local al punto que pasaría de ser burguesía agropecuaria y latifundista a convertirse en burguesía comercial (Ocampo, 1972), cuyo poder se incrementaría luego con la llegada del café a la región, la importancia de este producto para el desarrollo económico del país (Gallo, 1974), la interlocución que esto permitió con la clase política nacional a través de la Federación Nacional de Cafeteros (Christie, 1986; Ocampo, 1972), y la expansión de las vías de comunicación (Valencia, 1990).

La clase política que se configura al calor de estos acontecimientos va adquiriendo unas peculiaridades propias de su herencia antioqueña (Jaramillo, 2009, pp. 242-243), pero fortalecidas por su propio devenir, que giran en torno al carácter comunitario, con una fuerte influencia de valores como el conservatismo, la religión católica y el pasado febril de los arrieros, ingredientes del mito fundacional de raza pujante y diferente a los no pertenecientes a dicha élite (Santofimio, 2006, p. 316).

Puede evidenciarse así una estructura social que ya cuenta con las características de relación entre sectores dirigentes y dirigidos, entre una clase económica y políticamente dominante y una población dominada, entre una élite y la masa, entre la oligarquía y el pueblo llano (Platón, 1986; Aristóteles, 2004). Situación que puede rastrearse desde la Colonia Española misma, sea porque haya o no lazos de continuidad entre los dominantes de antaño y de hogaño, lo cual tiene aquí una importancia menor en la medida en que, como lo sostienen 
Mosca (1984) y Pareto (1980), en todas las formaciones sociales ha habido y hay gobernantes y gobernados. Los había en la Corona Española, que los trajo a América con algunas adaptaciones necesarias, y los había, por supuesto, en la sociedad indígena (Valencia, 2010) derrotada por los colonizadores. Los había en el Estado de Antioquia y los hubo luego en su provincia del sur, continuando luego en su etapa de departamento autónomo de Caldas.

\section{Formalización y Escisión del Gran Caldas.}

El 11 de abril de 1905, durante el gobierno de Rafael Reyes, fue oficialmente creado el departamento de Caldas mediante la Ley 17 de dicho año, la cual en su artículo tercero dice así:

Créase el Departamento de Caldas entre los Departamentos de Antioquia y Cauca, cuyo territorio estará delimitado así:

El río Arma, desde su nacimiento hasta el río Cauca; éste aguas arriba hasta la quebrada de Arquía, que es el límite de la Provincia de Marmato. Quedarán comprendidas dentro del Departamento de Caldas las Provincias de Robledo y Marmato, por los límites legales que hoy tienen, como también la Provincia del Sur del Departamento de Antioquia.

Parágrafo. La capital de este Departamento será la ciudad de Manizales (Congreso de la República de Colombia, 1905, p. 2).

Desde 1904 se venía discutiendo una nueva división territorial para Colombia, y esta unidad administrativa llamada finalmente Caldas (anteriormente se llamaba Córdoba) venía siendo contemplada, entre otras cosas, como forma de separar los departamentos de Antioquia (conservador) y Cauca (liberal), protagonistas de enconadas disputas armadas durante las guerras civiles del siglo XIX. "Esta propuesta venía siendo apoyada por los dirigentes Daniel Gutiérrez Arango y Aquilino Villegas, desde las columnas de El Correo del Sur y por Bonifacio Vélez, quien había sido Prefecto" (Valencia, 2015, p. 45). La protesta de Antioquia no tuvo el efecto de reversar la decisión, puesto que "la élite de Manizales empezaba a tener autonomía con relación a la de Medellín y logró mantener la designación del Departamento de Caldas como entidad independiente" (López y Correa, 2012, pp. 190-191).

A pesar de las afinidades culturales que alrededor del café se puedan encontrar entre las tres grandes regiones que este departamento unía, hubo profundas 
diferencias entre los sectores dirigentes de Armenia y Pereira con el nombramiento de Manizales como capital de todo el departamento. Lo cierto es que esta ciudad por aquel entonces concentraba buena parte del tráfico de mercancías desde y hacia el extranjero, seguía siendo nodo comercial, controlaba las principales rutas mercantiles y, por ende, vivía un momento privilegiado en materia económica, lo que la aventajaba frente a las demás ciudades del eje cafetero (Christie, 1986; Ocampo, 1972; Valencia, 1990).

En concordancia con lo anterior, la dirigencia manizaleña buscó dar el salto de pueblo a ciudad, con el objetivo de lograr coherencia entre su momento económico y su importancia nacional. Al respecto se diseñaron políticas para mejorar la arquitectura e infraestructura del municipio (Valencia, 2015, pp. 49-52), paralelo al fomento de la literatura, la historia, la exaltación del legado paisa y otras actividades culturales análogas, con el fin de conseguir un grado de diferenciación con pretensiones de superioridad, tanto en Manizales como en otros municipios cercanos (Christie, 1986; Jaramillo, 2009), idea muy cercana a la de aristocracia de Platón (1986).

Los grupos económicos fuertes seguían creciendo en los ámbitos agropecuario, cafetero y comercial, paralelamente al dominio político que mantenían sobre todo en el área de influencia de Manizales y las pretensiones de elevación literaria, arquitectónica y cultural (Jaramillo, 2009; Ocampo, 1972; Christie, 1986).

Sin embargo, hacia comienzos de la década del 30 Manizales iba perdiendo posición nacional con respecto a las cuatro principales ciudades del país (Bogotá, Medellín, Cali, Barranquilla) e incluso frente a la vecina Pereira en lo concerniente al desarrollo industrial (Jaramillo, 2008; Rodríguez, 1983). Si bien había algunas empresas industriales en Manizales, el verdadero impulso a este sector de la producción comenzó en la década del 50, y tuvo su mayor despliegue en los 60 de la mano del grupo de amigos conocido con el nombre de Los Azucenos (Ocampo, 1972; Jaramillo, 2008; Rodríguez, 1983).

Pertenecientes a las familias tradicionales de la ciudad, estos jóvenes llevaron a cabo labores de gestión empresarial tendientes a poner a Caldas y su capital como epicentro industrial de Colombia, tal como había ocurrido antes en los sectores comercial y cafetero. Incluso, el proceso estuvo acompañado del necesario correlato del desarrollo financiero con la creación del Banco de Caldas, Seguros Atlas, el Fondo Nacional del Café y, principalmente, la Corporación Financiera de Caldas, en la que la barra de Los Azucenos tuvo gran influencia (Rodríguez, 1983, pp. 60-65). Paralelamente, la clase política manizaleña hizo una apuesta por mantener su dominio de clase en materia política, para lo cual hizo inversiones en la creación de asociaciones de caridad, religiosas y sindicales afines a sus ideas (Drake, 1973). 
Como glosa valga decir que, en su estudio sobre el desarrollo industrial en el Viejo Caldas, Rodríguez (1983) muestra la configuración de los grupos empresariales y políticos de Manizales y Pereira y concluye, en sintonía con Coller (1999), que la oligarquía manizaleña siempre se ha mostrado más cerrada, contrario a la pereirana, lo cual puede repercutir en los desarrollos industriales ulteriores de ambas ciudades.

No obstante, el impulso rápidamente dio paso a una gran decepción, las empresas creadas o intervenidas se fueron extinguiendo poco a poco o se redujeron a mediocres resultados y el desarrollo industrial de Caldas se quedó en un simple anhelo frustrado. A este fracaso de la clase dirigente caldense se le sumó otro de enormes consecuencias para la historia reciente del departamento: la separación de Quindío y Risaralda en 1966.

Varias razones se aducen para explicar este acontecimiento, entre ellas el problema de las distancias entre Manizales y sectores más apartados como el Quindío, el desarrollo mostrado por Armenia y Pereira frente al estancamiento económico de la capital, las tensiones entre el norte conservador y el suroccidente liberal, incluso factores asociados al periodo de La Violencia, la autoproclamación heroica de los gestores de la "liberación" de Risaralda y Quindío entre otros (Alzate, 1984).

Pero uno de los factores decisivos tuvo que ver con el carácter exclusivista y gregario de la oligarquía manizaleña que desde siempre se esforzó por excluir a las dirigencias de Pereira y Armenia de las decisiones importantes del departamento y mantener el control económico de la región, para lo que concentró las instituciones y el presupuesto (Christie, 1986; López, 2011). Esto muestra uno de los efectos perversos de lo que Mills (1987) denomina élites monolíticas, o Bobbio (1982) llama oligarquía, sustentado en la tradición clásica.

En este punto el concepto de oligarquía sigue siendo útil para calificar a los grupos minoritarios de poder en Caldas, toda vez que sustentan su dominio en la posición económica y asumen rasgos aristocráticos que, sin embargo, no van en beneficio de la población, ergo devienen una forma pervertida de esta (Platón, 1986; Aristóteles, 2004; Rousseau 2004; Montesquieu, 1984). No obstante, la especialización de este grupo con respecto a las instancias de dirección administrativa hace que el concepto sea insuficiente, lo que hace más útil a la categoría de clase política (Alcántara y Llamazares, 1997) y en menor medida la de élite política.

\section{La clase política caldense después de la escisión}

Lo previamente dicho se confirma en este periodo (de 1980 a 2006) de la historia de Caldas, cuando los diferentes sucesos van a mostrar la profesionali- 
zación de una clase política (Alcántara y Llamazares, 1997), si bien con características elitistas y oligárquicas, alejada de los sectores tradicionales que mejor encajan en estas denominaciones. A raíz de la separación de Risaralda y Quindío, la clase política manizaleña tuvo vía libre para disponer del nuevo departamento a su antojo (Jaramillo, 2009). La época de los grecocaldenses o grecoquimbayas había quedado atrás; ahora comenzaba la era de los barrococaldenses, una forma de llamar a la clase dirigente que dispone de su región como de su propio negocio:

El paso de los grecocaldenses a los barrococaldenses, coincide con la partición de Caldas, lo que demuestra que el viejo Caldas era nacional, lo que se crean son provincias que pierden figuración nacional. A lo anterior, se le suma la crisis política ocasionada por el robo a Caldas, por parte de los senadores Ómar Yepes, Víctor Renán Barco, Dilia Estrada, Luis Guillermo Giraldo, el gobernador Guillermo Ocampo Ospina y otros, con el cual ocurre una pérdida de interés en el plano político por parte de la clase dirigente tradicional y una separación entre quienes manejan la empresa privada y quienes manejan la cosa pública (Jaramillo, 2009, pp. 244-245).

Aquí se expresa una forma de señalar a los caciques o gamonales locales, la forma más clientelar de manejar la política en las regiones, idea apoyada por Peralta (2010, p. 188), para quien la hegemonía barcoyepista tiene relación directa con la crisis social vivida por el departamento a finales de los 90. Esta tesis contrasta con lo dicho por Christie (1986, pp. 119-133), para quien el poder de los gamonales se vio reducido en la medida en que el Estado nacional lograba hacer mayor presencia en las regiones, lo cual ocurrió a partir de la década del 50 -algo en lo que coincide con Ansaldi (1991) y Becerra (2012).

Lo cierto es que, al margen de la controversia, el poder político en Caldas a partir de los 70 se concentró en manos de políticos profesionales, de acuerdo con Bolívar (2002) influyentes en el plano nacional y poseedores de un control administrativo y electoral prácticamente incontestable durante la época de la llamada "coalición barcoyepista", un pacto tácito entre los partidos Liberal y Conservador para repartirse por periodos los cargos públicos del departamento, especialmente la Gobernación de Caldas y la Alcaldía de Manizales; una especie de Frente Nacional caldense (Sierra, 1998). Esto último también fue propiciador de escándalos de corrupción como el denominado Robo a Caldas, el cual no tuvo ninguna consecuencia política importante el términos de pérdida de poder por parte de la clase que lo ostentaba (Jaramillo, 2009).

El enorme poder político que Barco, Yepes y Giraldo lograron acumular desde el Senado de la República fue tal que tuvieron una interlocución fluida con el Gobierno Nacional como cabezas visibles y líderes de sus respectivos 
partidos, lo que repercutió en la posibilidad de entrega de dádivas en los municipios de Caldas y que, a su vez, redundó en la reproducción de su hegemonía. La constitución de esta élite, pluralista en teoría pero monolítica en la práctica, tuvo variadas y negativas repercusiones para el departamento, entre las que se cuentan el cuestionamiento del ejercicio democrático en Caldas, la fractura con las élites tradicionales, el consecuente estancamiento económico de la región y la popularización y arraigo de prácticas politiqueras como la compra de votos y el clientelismo (Hernández, 2015, pp. 17-18).

El siglo XXI significó el comienzo del fin de la Coalición, algo que se expresó en la pérdida paulatina de algunas alcaldías menores, luego también la de Manizales, hasta perder la Gobernación de Caldas en 2013 (Hernández, 2015, pp. 25-31). La explicación de este fenómeno está dada por la apertura electoral de finales de los 80 y comienzos de los 90, el desgaste de la alianza, el retiro de los caciques del Senado y la emergencia de nuevos liderazgos (Jaramillo, 2009, p. 247 ) impulsados bajo la sombra de Álvaro Uribe, más la disidencia conservadora aupada por Luis Emilio Sierra (Hernández, 2015, p. 26).

Un hecho más que socavó la Coalición, sobre todo en lo concerniente al Partido Liberal, tuvo que ver con la revelación de las relaciones entre políticos pertenecientes a esta colectividad y grupos paramilitares de la región, fenómeno conocido como la Parapolítica. En este escándalo resultó condenado el llamado a ser heredero del emporio de Barco, Dixon Ferney Tapasco, también señalado de ser autor intelectual del asesinato del subdirector del diario La Patria, Orlando Sierra. Junto con él, otros militantes del partido rojo fueron sindicados y condenados, así como miembros del Partido de la U (Marín, 2011), uno de los supuestos nuevos liderazgos regionales, lo cual muestra que la susodicha alternativa de poder que estos partidos representaban sólo significó en muchos casos el regreso de las viejas oligarquías, ahora bajo un discurso autoritario.

Aparte de la falsa renovación política que representan los partidos uribistas en Caldas, y con un sector alternativo dividido y sin reales opciones de victoria, ahora el departamento se encuentra con que vuelven a la escena política los viejos representantes de la Coalición, Omar Yepes (La Patria, 2019a) y Luis Guillermo Giraldo (La Patria, 2019b), en una desesperanzadora pugna entre élites políticas que recuerda inevitable y tristemente la sentencia de Marx (1973) en El Dieciocho Brumario de Luis Bonaparte: "la historia se repite dos veces: la primera como tragedia y la segunda como farsa" (p. 408). 


\section{Conclusiones}

De la revisión hecha se puede concluir que el concepto de oligarquía suele ser el de mayor aplicación por los estudiosos de los grupos sociales dirigentes, aun si este no se ajusta en todos los casos a una rigurosa definición, o si existen diferencias en su utilización entre los teóricos que lo aplican. Es común todavía encontrar definiciones tendientes a referirse a los aspectos económicos del sector dirigente, mientras que otros apelan más bien tanto a esto como al factor político, el cual resulta esencial para esta categoría. Es característico de casi todos los autores un uso despectivo del término oligarquía, tal como ocurría en la Grecia clásica, lo cual muestra una continuidad semántica que posibilita, al menos en este aspecto, cierto grado de convergencia.

El concepto de élite política no goza de la misma fama que tiene en Estados Unidos, a pesar de que se lo asocie generalmente con el concepto de democracia, tan desarrollado en estas latitudes. Lo que puede aducirse al respecto es que la escuela marxista y demás teorías afines se han inclinado más por un concepto como el de oligarquía (cuando no por los más ideológicamente cargados de clase dominante o burguesía) para referirse a los sectores sociales con poder político.

En términos generales, pudo observarse que las diferencias conceptuales no son en realidad tan profundas ni categóricas y que quienes apelan a alguno de los mencionados términos suelen hacerlo indistintamente, en ocasiones incluso como sinónimos. Esto confirma la pertinencia de las categorías y criterios de análisis tenidos en cuenta para la realización de este artículo. El referente general, tanto del sentido común como del académico, apunta a un grupo social que posee una posición privilegiada en términos económicos y a veces también familiares, y que se caracteriza porque controla en buena medida las instituciones desde las cuales se ejerce el poder político. La relación entre este y el poder económico suele interpretarse como consustancial a la de cada uno de los conceptos.

A pesar de esto, se reafirma la idea de asumir el concepto de clase política como el de mayor utilidad para caracterizar el panorama político caldense, en la medida en que expresa mejor su situación concreta, especialmente la actual, sin dejar a un lado que no termina siendo suficiente para exponer el fenómeno, por lo que la apelación a los conceptos de oligarquía, élite y clase dominante siguen teniendo vigencia y, de paso, justifican el sincretismo hallado en los referentes bibliográficos.

Si bien conceptos como los de oligarquía y clase política son de regular utilización en el contexto colombiano, no se hallaron tantos estudios académicos al respecto y sí, por el contrario, se encontró una buena cantidad de referencias periodísticas, que en su mayoría hacen una aplicación sin rigor de estas categorías. Esto es un indicador del uso que hace el público general de conceptos como 
oligarquía y clase política, y muestra un divorcio entre la prensa y la academia que redunda en el tipo de influencia sobre el sentido común.

Puede apreciarse que en Caldas, particularmente en Manizales, ha habido desde su fundación un grupo cerrado de dirigentes políticos, una clase política monolítica que ha desplazado a otros sectores de la posibilidad de gobernar. En un momento de la historia se presentó una escisión entre la clase política y los sectores económicos, lo que llevó a que Caldas tuviera pobres desempeños empresariales y perdiera protagonismo en la escena nacional, con la consecuente perpetuación del mencionado grupo político en las posiciones administrativamente aventajadas. A pesar del cambio en la configuración de la clase política de los últimos años, no se vislumbra un panorama de pluralidad y más bien se observa cómo las viejas castas vuelven a la escena pública.

Finalmente, se remarca el uso del concepto de clase política como el más idóneo para nominar el fenómeno aquí abordado, en la medida en que hace énfasis en el aspecto propio de la facultad de decisión de un grupo social sobre los demás, y abarca lo central de las ideas de élite, oligarquía y clase dirigente. Se recuerda que el término clase no tiene en este caso la connotación marxista que lo vincula de forma exclusiva con los aspectos económicos y remite la política al mero plano de la superestructura. También queda claro que todavía queda mucho campo por abordar en esta materia, por ejemplo la mirada de la clase política desde la perspectiva latinoamericana, en particular desde los estudios decoloniales, lo cual puede ser materia de próximas investigaciones.

\section{Referencias}

Alcántara, M.; Llamazares, I. (1997). El análisis de los diputados latinoamericanos en el contexto de los estudios sobre la clase política. Características, objetivos y estrategias de investigación. América Latina Hoy, 16(8), 15-28. https://revistas.usal.es/index.php/1130-2887/article/view/2084

Alzate, G. (1984). Desmembración de la mariposa verde. Fondo Mixto de las Artes y la Cultura.

Anderson, P. (2018). La palabra H. Peripecias de la hegemonía. Akal.

Ansaldi, W. (1991). Frívola y casquivana, mano de hierro en guante de seda. Una propuesta para conceptualizar el término oligarquía en América Latina 
(Documento de trabajo).http://www.iunma.edu.ar/doc/MB/lic_historia_ mat_bibliografico/Historia\%20Latinoamericana\%20II/Unidad\%202/ Ansaldi\%20Frivola\%20y\%20casquivana\%20Oligarquia.pdf

Aristóteles (2004). La Política. Ediciones Universales.

Aron, R. (1950). Social Structure and the Ruling Class. The British Journal of Sociology, 1(1), 1-16. https://www-jstor-org.ezproxy.ucaldas.edu.co/ stable/pdf/587304.pdf?ab_segments $=0 \% 2$ Fbasic_search $\% 2$ Fcontrol\&refreqid=search\%3A072b487a0da4a 19b224289a742b655dc

Ávila, A. (2018, noviembre 14). La clase política colombiana [archivo de video]. https://www.youtube.com/watch?v=ZyaMn8Y8Nr4

Becerra, O. (2012, febrero 2). La oligarquía en América Latina [blog en línea]. http://blog.pucp.edu.pe/blog/orlandobecerra/2012/02/02/ la-oligarquia-en-america-latina/

Best, H.; Cotta, M. (2000). Elite Transformation and Modes of Representation since the Mid-nineteenth Century: Some Theoretical Considerations. En H. Best \& M. Cotta (Eds.). Parlamentary Representatives in Europe 1848-2000 (pp. 1-28). Oxford University Press.

Blondel, J.; Müller-Rommel, F. (2007). Political Elites. En J. D. Russell \& K. Hans-Dieter (Comps.). The Oxford Handbook of Political Behavior (pp. 818832). Oxford University Press.

Bobbio, N. (1981). Teoría de las Élites. En N. Bobbio \& N. Matteucci (Eds.). Diccionario de Política. A-J (Primera edición). Siglo XXI.

Bobbio, N. (1982). Oligarquía. En N. Bobbio \& N. Matteucci (Eds.). Diccionario de Política. L-Z (Primera edición). Siglo XXI.

Bolívar, R. (2002). La teoría de las élites en Pareto, Mosca y Michels. Iztapalapa, 52(1), 386-407. https://revistaiztapalapa.izt.uam.mx/index.php/izt/ article/view/494/647

Christie, K. (1986). Oligarcas, campesinos y política en Colombia. Universidad Nacional de Colombia. 
Coller, X. (1999). Circulación y conflicto en la élite política. El caso valenciano. Revista Valenciana d'Estudis Autonòmics, 29(4), 193-222. https://www. academia.edu/469864/Circulaci\%C3\%B3n_Y_Conflicto_En_La_Elite_ Pol\%C3\%ADtica._El_Caso_Valenciano

Congreso de la República de Colombia (1905). Ley 17 de 1905. https://www. alcaldiabogota.gov.co/sisjur/normas/Norma 1.jsp?i=13666

Dahl, R. (1958). A Critique of the Ruling Elite Model. The American Political Science Review, 52(2), 463-469. https://www-jstor-org.ezproxy.ucaldas.edu.co/stable/pdf/1952327.pdf?ab_segments=0\%2Fbasic_search\% 2 Fcontrol\&refreqid $=$ search $\% 3 \mathrm{~A} 455$ foodb5f85d888d $558 \mathrm{a} 60856 \mathrm{~b} 53 \mathrm{bca}$

De Los Ríos, R. (1983). Historia del Gran Caldas. Imprenta Departamental de Caldas.

Drake, G. F. (1973). Elites and Voluntary Associations: A Study of Community Power in Manizales, Colombia. (Tesis de doctorado). Universidad de Wisconsin. https://minds.wisconsin.edu/handle/1793/56719

Gallo, C. (1974). Hipótesis de la acumulación originaria de capital en Colombia. La Pulga.

Giraldo, L. G. (2015). Reseña sobre la historia política de Manizales. En A. Valencia \& F. Cantor (Comps.). Cátedra de historia regional de Manizales. Bernardo Arias Trujillo (pp. 351-382). Universidad de Caldas.

Gramsci, A. (1981). Cuadernos de la cárcel. Tomo I. Era.

Hernández, C. J. (2015). Cuando caen los caciques. Razones del auge y declive de la coalición barcoyepista en Caldas. Una mirada desde la literatura sobre política subnacional. Escribanía, 13(2), 11-34. http://revistasum. umanizales.edu.co/ojs/index.php/escribania/article/view/1426/1501

Hobbes, T. (1994). Leviatán. Fondo de Cultura Económica.

Jaramillo, J. (2008). Los Azucenos. El impulso de una generación de empresarios Manizaleños. Corporación Social Educadores y Empresarios del Comercio de Colombia. 
Jaramillo, O. (2009). La formación socioeconómica de Caldas y sus características políticas. Virajes, 11(1), 229-253. http://vip.ucaldas.edu.co/virajes/ downloads/Virajes 11_9.pdf

La Patria (febrero 24, 2019a). Luis Guillermo Giraldo vuelve al redil político en Caldas. Lapatria.com. http://www.lapatria.com/politica/luis-guillermogiraldo-vuelve-al-redil-politico-en-caldas-432353

La Patria (marzo 5, 2019b). Omar Yepes, otra vez a liderar el Conservatismo. LaPatria.com http://www.lapatria.com/manizales/omar-yepes-otra-vezliderar-el-conservatismo-432961

Lispet, M.; Rokkan, S. (1967). Party System and Voter Alignments. Mcmillan.

Locke, J. (1985). Ensayo sobre el gobierno civil. Orbis.

López, J. A. (2011). Movilización regionalista y nuevos poderes regionales: La fragmentación administrativa del Viejo Caldas y la creación de Risaralda. Sociedad y Economía, 21(2), 125-145. http://www.scielo.org.co/pdf/soec/ n21/n21a06.pdf

López, J. A.; Correa, J. J. (2012). Disputas por la centralización/descentralización administrativa en el Viejo Caldas, 1905-1966: Los casos de Manizales y Pereira. Anuario colombiano de historia social y de la cultura, 39(2), 187-216. http://www.scielo.org.co/pdf/achsc/v39n2/v39n2a08.pdf

Lukes, S. (2007). El poder. Un enfoque radical. Siglo XXI.

Marín, A. (mayo 22, 2011). El entramado de la parapolítica en Caldas. El Espectador.com https://www.elespectador.com/content/el-entramadode-la-parapol\%C3\%ADtica-en-caldas

Marx, K. (1973). El dieciocho brumario de Luis Bonaparte. En K. Marx y F. Engels (Comps.). Obras escogidas. Tomo I (pp. 404-498). Progreso.

Marx, K.; Engels, F. (1973). Feuerbach. Oposición entre las concepciones materialista e idealista. En K. Marx y F. Engels (Comps.). Obras escogidas. Tomo I (pp. 11-81). Progreso. 
Michels, R. (1972). Los partidos políticos II. Un estudio sociológico de las tendencias oligárquicas de la democracia moderna. Amorrortu.

Mills, C. W. (1987). La élite del poder. Fondo de Cultura Económica.

Montesquieu (1984). El espiritu de las leyes. Orbis.

Mosca, G. (1984). La clase política. Fondo de Cultura Económica.

Ocampo, J. F. (1972). Dominio de clase en la ciudad colombiana. La oveja negra.

Pareto, V. (1980). Forma y equilibrio sociales: extracto del tratado de Sociología general. Alianza editorial.

Peralta, B. (2010). La descentralización municipal y su relación con la autonomía local y el desarrollo sociopolítico en el departamento de Caldas, 1988-2000. Jurídicas, 7(1), 182-230. https://doctrina.vlex.com.co/vid/municipalsociopolitico-departamento-caldas-232685025

Platón (1986). La República. Bedout.

Putman, R. (1976). The Comparative Study of Political Elites. Eaglewood Cliffs.

Rivas, J. M. (2016). Violencia y nepotismo: La trayectoria de la élite política colombiana y sus cambios en los últimos cuarenta años. Iberoamericana, 63(11), 245-249. https://journals.iai.spk-berlin.de/index.php/iberoamericana/ article/view/2300/1902

Rodríguez, M. (1983). El empresario industrial en el viejo Caldas. Uniandes.

Rousseau, J. J. (2004). El contrato social. Ediciones Universales.

Santofimio, R. (2006). Cultura política y la política de la Cultura: ¿Dónde está el anclaje? Aspectos conceptuales y de análisis para la comprensión de la participación política en Manizales y el departamento de Caldas (Colombia). Virajes, 8(1), 297-320. http://vip.ucaldas.edu.co/virajes/ downloads/Virajes8_11.pdf 
Sartori, G. (1970). Concept Misinformation in Comparative Politics. The American Political Science Review, 64(4), 1033-1053. http://www.la.utexas. edu/users/chenry/core/Course\%20Materials/Sartori/o.pdf

Schmitter, P. (1985). Neocorporatismo y Estado. Reis, 31(3), 47-78. http://reis. cis.es/REIS/PDF/REIS_031_05.pdf

Schumpeter, J. A. (1983). Capitalismo, socialismo y democracia. Orbis.

Sierra, O. (1998). Caldas: escenario electoral prefabricado. En J. Rodríguez (Ed.). Democracia, política y paz. Elecciones en el Eje Cafetero (pp. 1-76). Editorial La Patria.

Valencia, A. (1990). Manizales en la dinámica colonizadora. Universidad de Caldas.

Valencia, A. (2010). Raíces en el tiempo. La región Caldense. Secretaría de Cultura de Caldas.

Valencia, A. (2015). Un contexto para la historia de Manizales. En A. Valencia \& F. Cantor (Comps.). Cátedra de historia regional de Manizales. Bernardo Arias Trujillo (pp. 31-65). Universidad de Caldas. 
Esta revista se terminó de imprimir en el mes de febrero de 2021, en Matiz Taller Editorial

Manizales - Colombia 